Check for updates

Cite this: Mater. Adv., 2021,

2, 1402
Received 28th October 2020, Accepted 14th January 2021

DOI: 10.1039/d0ma00841a

rsc.li/materials-advances

\section{Dual-emissive $\mathrm{Ln}^{3+} / \mathrm{Mn}^{4+}$ Co-doped double perovskite phosphor via site-beneficial occupation $\dagger$}

\author{
Yueyue Song, ${ }^{a}$ Ning Guo, (D) *a Jing Li, ${ }^{a}$ Yanmei Xin, ${ }^{a}$ Wei Lüb and Yuqing Miao ${ }^{a}$
}

\begin{abstract}
The non-contact temperature detectors based on fluorescence intensity ratio (FIR) technology have been widely studied. In the past few decades, researchers have been working on optical temperature measurement via FIR technology based on the two thermally-coupled energy levels (TCLs) of rare-earth ions. However, the FIR method based on TCLs has inherent limitations, which hinder further improvement of relative sensitivity $\left(S_{r}\right)$. In order to further improve the temperature measurement performance, we have designed a dual-activator luminescence system of $\mathrm{La}_{2} \mathrm{LiSbO}_{6}$ (LLSO) perovskite co-doped with rare-earth $\left(\mathrm{Tb}^{3+}, \mathrm{Dy}^{3+}\right)$ ions and transition metal $\left(\mathrm{Mn}^{4+}\right)$ ions according to the sitebeneficial occupation principle. LLSO provides suitable occupation sites for $\mathrm{Tb}^{3+} / \mathrm{Dy}^{3+}$ ions and $\mathrm{Mn}^{4+}$ ions. The experimental results show that these doped ions can enter the matrix successfully and emit luminescence simultaneously. The emission peaks of $\mathrm{Tb}^{3+} / \mathrm{Dy}^{3+}$ ions and $\mathrm{Mn}^{4+}$ ions are well separated, which provides a good signal identification ability for temperature detection. In addition, $\mathrm{Tb}^{3+} / \mathrm{Dy}^{3+}$ ions and $\mathrm{Mn}^{4+}$ ions have different sensitivities to the environment due to their different external electronic configurations, which leads to different thermal quenching responses of their fluorescence emission intensity. The decline rate of $\mathrm{Mn}^{4+}$ ions is much faster than that of $\mathrm{Tb}^{3+} / \mathrm{Dy}^{3+}$ ions, which is very useful for temperature measurement based on FIR technology. Therefore, $\mathrm{Tb}^{3+} / \mathrm{Dy}^{3+}$ ions can be used as reference signals, whereas $\mathrm{Mn}^{4+}$ ions are suitable detection signals. We have investigated the temperature detection performance at different luminescent positions of luminescent ions. The results show that the fluorescence intensity ratio between $\mathrm{Tb}^{3+} / \mathrm{Dy}^{3+}$ ions and $\mathrm{Mn}^{4+}$ ions in the materials exhibits excellent temperature sensing performance in the temperature range of 303-523 $\mathrm{K}$. The maximum relative sensitivity and absolute sensitivity of $\mathrm{Tb}^{3+}$ and $\mathrm{Mn}^{4+}$ co-doped LLSO phosphors are $0.946 \% \mathrm{~K}^{-1}$ and $0.00193 \mathrm{~K}^{-1}$, respectively; the maximum relative sensitivity and absolute sensitivity of $\mathrm{Dy}^{3+}$ and $\mathrm{Mn}^{4+}$ co-doped LLSO phosphors are $0.796 \% \mathrm{~K}^{-1}$ and $0.00832 \mathrm{~K}^{-1}$, respectively, which are much higher than those of some optical thermometric materials reported previously. The self-reference optical temperature measurement method based on double luminescent centers proposed in this paper can provide a new viewpoint for the development of high-performance thermometers.
\end{abstract}

\section{Introduction}

So far, luminescent materials constituting of luminescent ions and a host have been widely applied in white light-emitting diodes (W-LEDs), three-dimensional displays, medical equipment, temperature sensing and other fields. ${ }^{1-9}$ In recent years, the use of fluorescent materials as optical thermometers has

\footnotetext{
${ }^{a}$ Department of Chemistry, University of Shanghai for Science and Technology, Shanghai 200093, P. R. China. E-mail: guoning@usst.edu.cn; Fax: +86-21-65711344; Tel: +86-21-65711344

${ }^{b}$ School of Electrical Engineering and Intelligentization, Dongguan University of Technology, Dongguan 523808, P. R. China

$\dagger$ Electronic supplementary information (ESI) available. See DOI: 10.1039/ d0ma00841a
}

attracted considerable attention of researchers because of their advantages of non-contact, real-time measurement, high spatial resolution and high accuracy. ${ }^{10-15}$ The contactless fluorescent temperature indicators overcome the shortcomings of traditional thermometers and are implemented far and wide in substances with small size or in harsh environment. ${ }^{16,17}$

Generally speaking, the matrix materials for optical temperature measurement include nanorods, nanoparticles, core-shell particles, glass ceramics containing fluorine nanocrystals and oxide blocks. ${ }^{18-22}$ This means that the phosphor can be resistant to oxidation and high temperature, and not react in harsh environment and remain stable. Trivalent lanthanide ions and some transition group ions are used as luminescent centers or activators in optical thermometry. Fluorescence temperature 
measurement is realized by monitoring the luminescent signal related to temperature, such as fluorescence intensity, peak position, bandwidth, fluorescence lifetime, and fluorescence intensity ratio (FIR). ${ }^{23-30}$ The temperature detection method based on FIR has the advantages of self-reference and is not affected by external factors except temperature; it has superiorities over other temperature measurement methods and has been widely applied. Generally speaking, most optical thermometers using FIR technology are based on two thermally-coupled energy levels (TCLs) of rare-earth ions, such as $\operatorname{Er}^{3+}\left({ }^{2} \mathrm{H}_{11 / 2}\right.$ and $\left.{ }^{4} \mathrm{~S}_{3 / 2}\right)$; $\mathrm{Nd}^{3+}\left({ }^{4} \mathrm{~F}_{5 / 2}\right.$ and $\left.{ }^{4} \mathrm{~F}_{3 / 2}\right)$; $\mathrm{Dy}^{3+}\left({ }^{4} \mathrm{I}_{5 / 2}\right.$ and $\left.{ }^{4} \mathrm{~F}_{9 / 2}\right)$; and $\mathrm{Eu}^{3+}\left({ }^{5} \mathrm{D}_{1}\right.$ and $\left.{ }^{5} \mathrm{D}_{0}\right) \cdot{ }^{10,14,31-35}$ For temperature sensors based on TCLs, FIR obeys the Boltzmann distribution law, so relative sensitivity $(\mathrm{Sr})$ is proportional to the corresponding TCL energy gap. However, the range of TCLs is generally $200-2000 \mathrm{~cm}^{-1}$, which makes it difficult to further improve Sr. In order to find an efficient FIR method to improve the performance of temperature measurement, the emission of different activation centers must overcome the inherent limitations of the FIR method based on TCLs, and provide a possibility for efficient temperature measurement. One of the emitting centers is used as the temperature probe and the other as the reference center. The emission intensity of activators usually decreases with the increase of temperature, but the quenching degree of different activators varies with temperature, one of which is faster and the other is slower, resulting in a large difference in FIR values between the two activators at different temperatures, so as to improve the temperature measurement performance. Rare-earth (RE) ions are a kind of special optical probes because their $4 \mathrm{f}$ active electrons are shielded by external electron sublayers, which makes them less sensitive to the environment, but enough to observe changes. $^{36}$ Transition metal (TM) ions have a $3 \mathrm{~d}^{n}$ electronic configuration and are very sensitive to the surrounding environment. Therefore, the emission of TM ions is more affected by temperature than that of RE ions. Therefore, the dependence of $\mathrm{TM}$ ions and trivalent RE ions on temperature is different. It is expected that FIR based on TM ions and trivalent RE ions will change greatly with temperature, which should have high temperature sensitivity. In recent years, as a transition metal activator, $\mathrm{Mn}^{4+}$ has attracted much attention due to its low cost, deep red emission and wide excitation band. ${ }^{37-40}$

As is known, it is also very important to choose a suitable matrix as the carrier of activators. Not all matrix-doped ions can emit light, but if the matrix provides suitable sites for the doped ions to replace, then they can emit fluorescence. For example, the luminescence and thermometric properties of $\mathrm{NaLaMgWO}_{6}: \mathrm{Eu}^{3+}, \mathrm{Mn}^{4+}$ phosphors were studied by Zhou et $a .^{41}$ In the ${ }^{4 a L a M g W O}{ }_{6}$ matrix, $\mathrm{Eu}^{3+}$ ions often replace $\mathrm{La}^{3+}$ sites. Similarly, $\mathrm{Mn}^{4+}$ ions are more likely to replace $\mathrm{W}^{6+}$ ion sites. Double perovskite compounds have attracted much attention due to their high stability and low price. $\mathrm{La}_{2} \mathrm{LiSbO}_{6}$ is a typical perovskite structure, which is composed of $\left[\mathrm{LiO}_{6}\right]$, $\left[\mathrm{SbO}_{6}\right]$ octahedron and $\left[\mathrm{LaO}_{8}\right]$ dodecahedron. The crystal structure of the $\mathrm{La}_{2} \mathrm{LiSbO}_{6}$ compound was first reported by López et al. in $1990 .{ }^{42}$ Its structure is monoclinic $\mathrm{GdFeO}_{3}$ type perovskite. A large number of octahedral sites in $\mathrm{La}_{2} \mathrm{LiSbO}_{6}$ (LLSO) are favorable for $\mathrm{Mn}^{4+}$ ions to enter the structure and promote luminescence. In this work, novel LLSO: $\mathrm{Tb}^{3+}, \mathrm{Mn}^{4+}$ and LLSO: $\mathrm{Dy}^{3+}, \mathrm{Mn}^{4+}$ phosphors with strong efficient dualactivator luminescence are devised and synthesized by a hightemperature solid-state method. LLSO host provides favorable site occupation for $\mathrm{Mn}^{4+}$ and $\mathrm{Tb}^{3+} / \mathrm{Dy}^{3+}$, specifically $\mathrm{Mn}^{4+}$ occupies the $\mathrm{Sb}$ site and $\mathrm{Tb}^{3+} / \mathrm{Dy}^{3+}$ occupies the La site, and makes them emit fluorescence. The luminescence properties and temperature dependence of these phosphors were tested and analyzed in detail, which showed their application prospects in optical temperature sensors.

\section{Experimental section}

\subsection{Synthesis of samples}

LLSO:0.005 $\mathrm{Mn}^{4+}$, LLSO:0.09 $\mathrm{Tb}^{3+}, 0.005 \mathrm{Mn}^{4+}$ and LLSO:0.09$\mathrm{Dy}^{3+}, 0.005 \mathrm{Mn}^{4+}$ (the unit is mol\%) phosphors and LLSO host were successfully synthesized via a high-temperature solid-state method. $\mathrm{La}_{2} \mathrm{O}_{3}$ (A.R.), $\mathrm{Li}_{2} \mathrm{CO}_{3}$ (A.R.), $\mathrm{Sb}_{2} \mathrm{O}_{3}$ (A.R.), $\mathrm{MnCO}_{3}$ (A.R.), $\mathrm{Dy}_{2} \mathrm{O}_{3}(\geq 99.9 \%), \mathrm{Tb}_{4} \mathrm{O}_{7}(99.99 \%)$ as raw materials were weighed according to the stoichiometric ratio, in which $\mathrm{Li}_{2} \mathrm{CO}_{3}$ was over
(A)

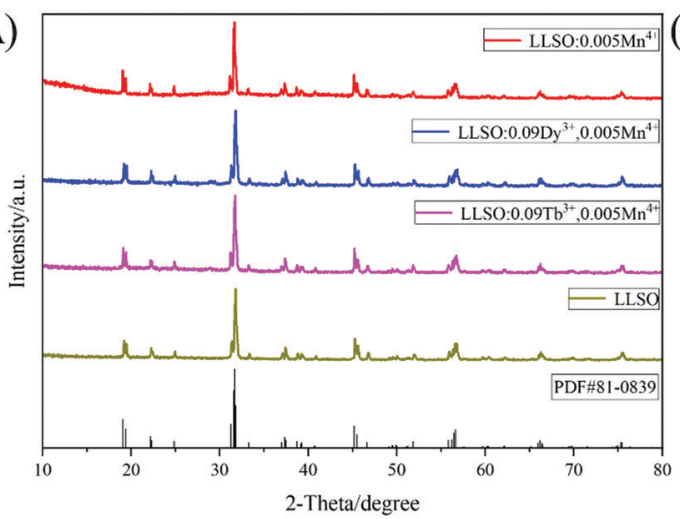

(B)
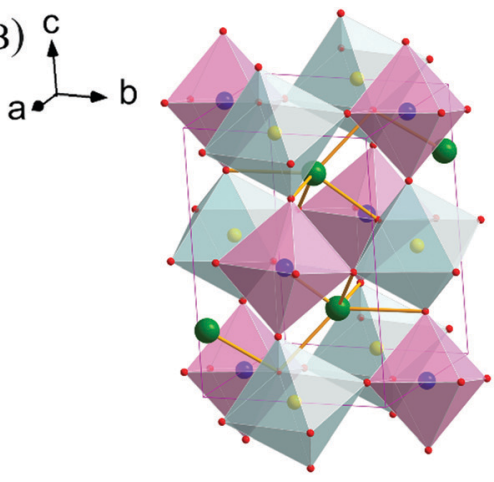

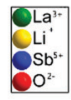

Fig. 1 (A) XRD patterns of LLSO: $0.005 \mathrm{Mn}^{4+}$; LLSO: $0.09 \mathrm{~Tb}^{3+}, 0.005 \mathrm{Mn}^{4+}$; LLSO: $0.09 \mathrm{Dy}^{3+}, 0.005 \mathrm{Mn}^{4+}$ and LLSO host. (B) Crystal structure schematic diagram of $\mathrm{La}_{2} \mathrm{LiSbO}_{6}$. 
$3 \%$. The raw materials were mixed and ground thoroughly in an agate mortar for $30 \mathrm{~min}$. After full grinding, the mixed powder was transferred into an alumina crucible and calcined in air at $1200{ }^{\circ} \mathrm{C}$ for $2 \mathrm{~h}$. After cooling to room temperature, the intermediate was taken out and ground into powder, and then returned to the crucible for repeated calcination. After cooling again, the product was ground into powder and put into a sample tube for testing.

\subsection{Measurement and characterization}

X-ray powder diffraction (XRD) of the samples was performed using an X-ray diffractometer (Bruker D8) containing $\mathrm{Cu} \mathrm{K} \alpha$ radiation ( $\lambda=1.5418 \AA$ ) with the operating conditions of $40 \mathrm{kV}$ and $15 \mathrm{~mA}$, and the XRD patterns were collected in the range of $10^{\circ}-80^{\circ}$ with the scanning steps of 0.02 . The photoluminescence excitation (PLE) and emission (PL) spectra of samples were measured using a Hitachi F-7000 fluorescence spectrometer at room temperature with a $150 \mathrm{~W}$ xenon lamp as the excitation source. The quantum yields and decay curves of the samples were measured by an Edinburgh FS5 spectrophotometer; temperature-dependent photoluminescence (PL) characteristics were monitored via this spectrophotometer combined with a heating device (TAP 02).

\section{Results and discussion}

\subsection{Crystal structure}

The crystal structures of $\mathrm{Mn}^{4+}$ doped LLSO phosphors, $\mathrm{Tb}^{3+} /$ $\mathrm{Mn}^{4+}$ and $\mathrm{Dy}^{3+} / \mathrm{Mn}^{4+}$ co-doped LLSO phosphors as well as undoped samples were identified from the XRD patterns, as shown in Fig. 1(A). The diffraction peaks of the LLSO host match well with the standard card of LLSO (PDF\#81-0839), indicating that the host has been successfully prepared. The XRD diffraction peaks of single doped and co-doped samples are consistent with those of LLSO, which proves that the introduction of $\mathrm{Mn}^{4+}, \mathrm{Tb}^{3+} / \mathrm{Mn}^{4+}$ or $\mathrm{Dy}^{3+} / \mathrm{Mn}^{4+}$ do not produce any impurity phase and cannot change the crystal structure. This indicates that these dopants are successfully incorporated into the LLSO host. Fig. 1(B) presents the crystal structure of the LLSO matrix. It is clearly seen that $\left[\mathrm{LiO}_{6}\right]$ and $\left[\mathrm{SbO}_{6}\right]$ connect with each other alternately through a common site to form octahedral chains, which is conducive to the entry of $\mathrm{Mn}^{4+}$ ions into its structure and promotes the luminescence of $\mathrm{Mn}^{4+}$ ions. $\mathrm{La}^{3+}$ ions occupy the eight-coordination sites. Considering the probable mechanism of effective ionic radii and coordination number $(\mathrm{CN})$ of $\mathrm{Mn}^{4+}$ ion $(0.53 \AA, \mathrm{CN}=6)$ and $\mathrm{Sb}^{5+}(0.60 \AA$, $\mathrm{CN}=6$ ), it is easier for the $\mathrm{Mn}^{4+}$ activator to enter the $\mathrm{Sb}^{5+}$ locus. Similarly, $\mathrm{Tb}^{3+} / \mathrm{Dy}^{3+}$ ions prefer to replace the $\mathrm{La}^{3+}$ locus, which can be proved by calculating the value of the radius difference percentage $\left(D_{\mathrm{r}}\right)$, which is reported by Davolos ${ }^{43}$ and needs to be within $30 \%$. The $D_{\mathrm{r}}$ values can be calculated using the equation:

$$
D_{\mathrm{r}}=\frac{R_{\mathrm{m}}(\mathrm{CN})-R_{\mathrm{d}}(\mathrm{CN})}{R_{\mathrm{m}}(\mathrm{CN})} \times 100 \%
$$

where $R_{\mathrm{m}}$ and $R_{\mathrm{d}}$ are the radii of matrix cations and doped cations, respectively. $\mathrm{CN}$ is the coordination number. The $D_{\mathrm{r}}$ values between matrix cations and doped cations are listed in
Table 1 The $D_{\mathrm{r}}$ values between matrix cations and doped cations

\begin{tabular}{lllll}
\hline Matrix cations $(\mathrm{CN})$ & Doped cations $(\mathrm{CN})$ & $R_{\mathrm{m}} / \AA$ & $R_{\mathrm{d}} / \AA$ & $D_{\mathrm{r}} / \%$ \\
\hline $\mathrm{Li}^{+}(6)$ & $\mathrm{Mn}^{4+}(6)$ & 0.76 & 0.530 & 30.26 \\
$\mathrm{Sb}^{5+}(6)$ & $\mathrm{Mn}^{4+}(6)$ & 0.60 & 0.530 & 11.67 \\
$\mathrm{Li}^{+}(6)$ & $\mathrm{Tb}^{3+}(6)$ & 0.76 & 0.923 & -21.45 \\
$\mathrm{La}^{3+}(8)$ & $\mathrm{Tb}^{3+}(8)$ & 1.160 & 1.040 & 10.34 \\
$\mathrm{Sb}^{5+}(6)$ & $\mathrm{Tb}^{3+}(6)$ & 0.60 & 0.923 & -53.83 \\
$\mathrm{Li}^{+}(6)$ & $\mathrm{Dy}^{3+}(6)$ & 0.76 & 0.912 & -20 \\
$\mathrm{La}^{3+}(8)$ & $\mathrm{Dy}^{3+}(8)$ & 1.160 & 1.027 & 11.47 \\
$\mathrm{Sb}^{5+}(6)$ & $\mathrm{Dy}^{3+}(6)$ & 0.60 & 0.912 & -52
\end{tabular}
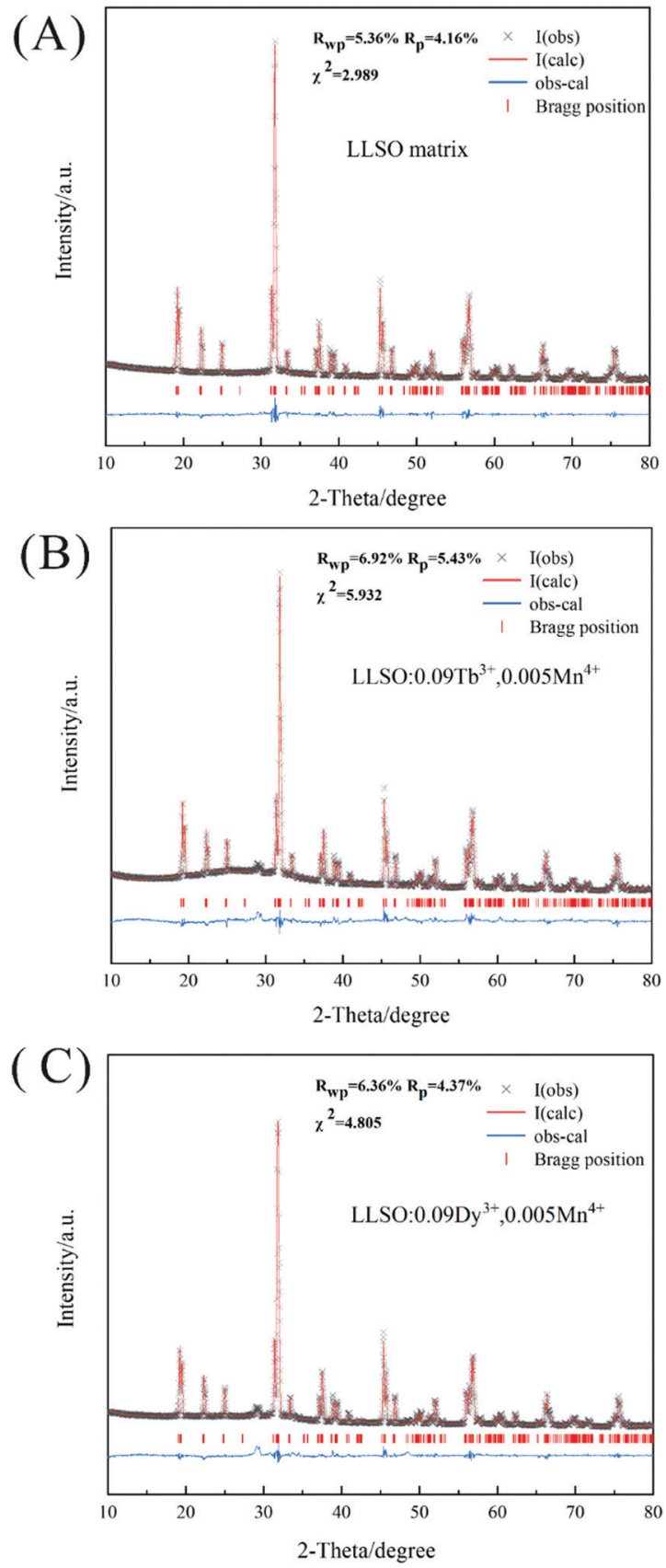

Fig. 2 Rietveld refinement patterns for $X$-ray diffraction patterns of (A) LLSO matrix; (B) LLSO: $0.09 \mathrm{~Tb}^{3+}, 0.005 \mathrm{Mn}^{4+}$ and (C) LLSO: 0.09Dy ${ }^{3+}$, $0.005 \mathrm{Mn}^{4+}$. 
Table 2 The relevant Rietveld refinement parameters and crystallographic data

\begin{tabular}{llll}
\hline Parameter & $\begin{array}{l}\text { LLSO } \\
\text { matrix }\end{array}$ & $\begin{array}{l}\text { LLSO:0.09Tb } \\
0.005 \mathrm{Mn}^{4+}\end{array}$ & $\begin{array}{l}\mathrm{LLSO}^{4+} 0.09 \mathrm{Dy}^{3+} \\
0.005 \mathrm{Mn}^{4+}\end{array}$ \\
\hline space group & $P 2_{1} / n(14)$ & $P 2_{1} / n(14)$ & $P 2_{1} / n(14)$ \\
$a(\AA)$ & 5.6195 & 5.6134 & 5.6137 \\
$b(\AA)$ & 5.7236 & 5.7278 & 5.7259 \\
$c(\AA)$ & 7.9670 & 7.9607 & 7.9605 \\
$\alpha=\gamma(\mathrm{deg})$ & 90.000 & 90.000 & 90.000 \\
$\beta(\mathrm{deg})$ & 89.776 & 89.742 & 89.745 \\
$V\left(\AA^{3}\right)$ & 256.247 & 255.953 & 255.876 \\
Units, $Z$ & 2 & 2 & 2 \\
$R_{\mathrm{p}}(\%)$ & 4.16 & 5.43 & 4.37 \\
$R_{\mathrm{wp}}(\%)$ & 5.36 & 6.92 & 6.36 \\
$\chi^{2}$ & 2.989 & 5.932 & 4.805 \\
& & &
\end{tabular}

Table 1. It can be clearly seen that $\mathrm{Mn}^{4+}$ ions will replace $\mathrm{Sb}^{5+}$ sites in the matrix, and $\mathrm{Tb}^{3+} / \mathrm{Dy}^{3+}$ ions can be doped into $\mathrm{La}^{3+}$ sites.

Fig. S1 (ESI $\dagger$ ) shows the SEM images of each sample. It is not difficult to see that the samples exhibit irregular particle sizes in the range of 1-3 $\mu \mathrm{m}$. In order to further confirm the structure of the synthesized samples, the standard data of LLSO were used as a reference, and Rietveld refinement of the existing samples was performed using GASA software. The final refinement mode is shown in Fig. 2, and the relevant refining parameters and crystallographic data are summarized in Table 2. The obtained final refinement parameters $\left(R_{\mathrm{wp}}, R_{\mathrm{p}}\right.$ and $\chi$ ) show that the actual structure is in good agreement with the initial structure. The $V$ values of the co-doped samples decreased because $\mathrm{Tb}^{3+}(1.040 \AA, \mathrm{CN}=8) / \mathrm{Dy}^{3+}(1.027 \AA, \mathrm{CN}=8)$ and $\mathrm{Mn}^{4+}(0.530 \AA, \mathrm{CN}=6)$ replaced $\mathrm{La}^{3+}(1.160 \AA, \mathrm{CN}=8)$ and $\mathrm{Sb}^{5+}(0.60 \AA, \mathrm{CN}=6)$ sites, respectively, in the crystal lattice.

\subsection{Fluorescence properties and optical thermometry}

Fig. 3 shows the PL and PLE spectra of $\mathrm{Mn}^{4+}$ single-doped LLSO and $\mathrm{Dy}^{3+} / \mathrm{Tb}^{3+}, \mathrm{Mn}^{4+}$ co-doped LLSO phosphors at room temperature. The excitation peaks in the range of $260-280 \mathrm{~nm}$ are due to the charge transfer of electrons from the oxygen ligands to the central metal atom. As shown in Fig. 3(A), the PL spectrum with $315 \mathrm{~nm}$ excitation wavelength presents an emission band centered at $713 \mathrm{~nm}$, which originates from the spin-forbidden ${ }^{2} \mathrm{E} \rightarrow{ }^{4} \mathrm{~A}_{2}$ transition of the $\mathrm{Mn}^{4+}$ ion. The PLE spectrum of $\mathrm{Mn}^{4+}$ monitored at $713 \mathrm{~nm}$ shows a wide hump in the range of $250-400 \mathrm{~nm}$, three peaks centered at $276 \mathrm{~nm}$, $319 \mathrm{~nm}$ and $354 \mathrm{~nm}$ were fitted by Gaussian peak splitting, and are due to the charge transfer (CT) from $\mathrm{O}^{2-}$ to $\mathrm{Mn}^{4+},{ }^{4} \mathrm{~A}_{2} \rightarrow{ }^{4} \mathrm{~T}_{1}$ and ${ }^{4} \mathrm{~A}_{2} \rightarrow{ }^{2} \mathrm{~T}_{2}$ spin-allowed transitions of $\mathrm{Mn}^{4+}$, respectively. The excitation peak at $480 \mathrm{~nm}$ corresponds to the $\mathrm{Mn}^{4+}:{ }^{4} \mathrm{~A}_{2} \rightarrow{ }^{4} \mathrm{~T}_{2}$ spin-forbidden transitions. Fig. 3[(B)a] illustrates the PLE spectrum of $\mathrm{Tb}^{3+}$ and $\mathrm{Mn}^{4+}$ ions co-doped LLSO phosphor, which was monitored at $544 \mathrm{~nm}$. It consists of a broad band centered at $276 \mathrm{~nm}$ that is attributed to the charge transfer (CT) from $\mathrm{O}^{2-}$ to $\mathrm{Tb}^{3+}$ and the peaks between $300-385 \mathrm{~nm}$ are attributed to $4 \mathrm{f} \rightarrow 4 \mathrm{f}$ transitions of $\mathrm{Tb}^{3+}$. Under $276 \mathrm{~nm}$ excitation, the emission spectrum of LLSO: $\mathrm{Tb}^{3+}, \mathrm{Mn}^{4+}$ phosphor shows a series of sharp peaks at $492 \mathrm{~nm}, 544 \mathrm{~nm}, 591 \mathrm{~nm}$ and $624 \mathrm{~nm}$ as emission centers, which are ${ }^{5} \mathrm{D}_{4} \rightarrow{ }^{7} \mathrm{~F}_{J}(J=6,5,4$, and 3) transitions. In addition, two weak emission peaks at $416 \mathrm{~nm}$ and $439 \mathrm{~nm}$ are due to ${ }^{5} \mathrm{D}_{3} \rightarrow{ }^{7} \mathrm{~F}_{5}$ and ${ }^{5} \mathrm{D}_{3} \rightarrow{ }^{7} \mathrm{~F}_{4}$ transitions, respectively. As depicted in Fig. $3[(\mathrm{~B}) \mathrm{b}]$, the PLE spectrum of LLSO:Dy ${ }^{3+}, \mathrm{Mn}^{4+}$ phosphor, monitored at $577 \mathrm{~nm}$ emission wavelength displays several excitation bands centered at $350 \mathrm{~nm}, 365 \mathrm{~nm}, 388 \mathrm{~nm}$ and $427 \mathrm{~nm}$ attributed to ${ }^{6} \mathrm{H}_{15 / 2} \rightarrow{ }^{6} \mathrm{P}_{7 / 2},{ }^{6} \mathrm{H}_{15 / 2} \rightarrow{ }^{6} \mathrm{P}_{5 / 2},{ }^{6} \mathrm{H}_{15 / 2} \rightarrow{ }^{4} \mathrm{I}_{13 / 2}$, and ${ }^{6} \mathrm{H}_{15 / 2} \rightarrow{ }^{4} \mathrm{G}_{11 / 2}$ transitions, respectively. The PL spectrum under $274 \mathrm{~nm}$ excitation exhibits two characteristic emission peaks at $484 \mathrm{~nm}$ and $576 \mathrm{~nm}$ that are attributed to ${ }^{4} \mathrm{~F}_{9 / 2} \rightarrow{ }^{6} \mathrm{H}_{15 / 2}$ and ${ }^{4} \mathrm{~F}_{9 / 2}$ $\rightarrow{ }^{6} \mathrm{H}_{13 / 2}$ transitions, respectively. In the PL and PLE spectra of the co-doped phosphors, the characteristic peaks of $\mathrm{Mn}^{4+}$ ions are clearly presented. We measured the quantum yields of the doubledoped samples. The quantum yield of LLSO:0.09 $\mathrm{Tb}^{3+}, 0.005 \mathrm{Mn}^{4+}$ phosphor was up to $45.95 \%$, while the quantum yield of LLSO:0.09Dy ${ }^{3+}, 0.005 \mathrm{Mn}^{4+}$ phosphor was $23.42 \%$.

In order to further study whether there is energy transfer between $\mathrm{Ln}^{3+}$ and $\mathrm{Mn}^{4+}$, we analyzed the decay curves of samples with different concentrations, as shown in Fig. S2 (ESI $\dagger$ ). It can be seen that with the increase of $\mathrm{Tb}^{3+}$ concentration, the lifetime of $\mathrm{Mn}^{4+}$ does not increase obviously, so there is no energy transfer from $\mathrm{Tb}^{3+}$ to $\mathrm{Mn}^{4+}$. However, with the increase of $\mathrm{Dy}^{3+}$ concentration, the lifetime of $\mathrm{Mn}^{4+}$ decreases, so there is no energy transfer from $\mathrm{Dy}^{3+}$ to $\mathrm{Mn}^{4+}$ as
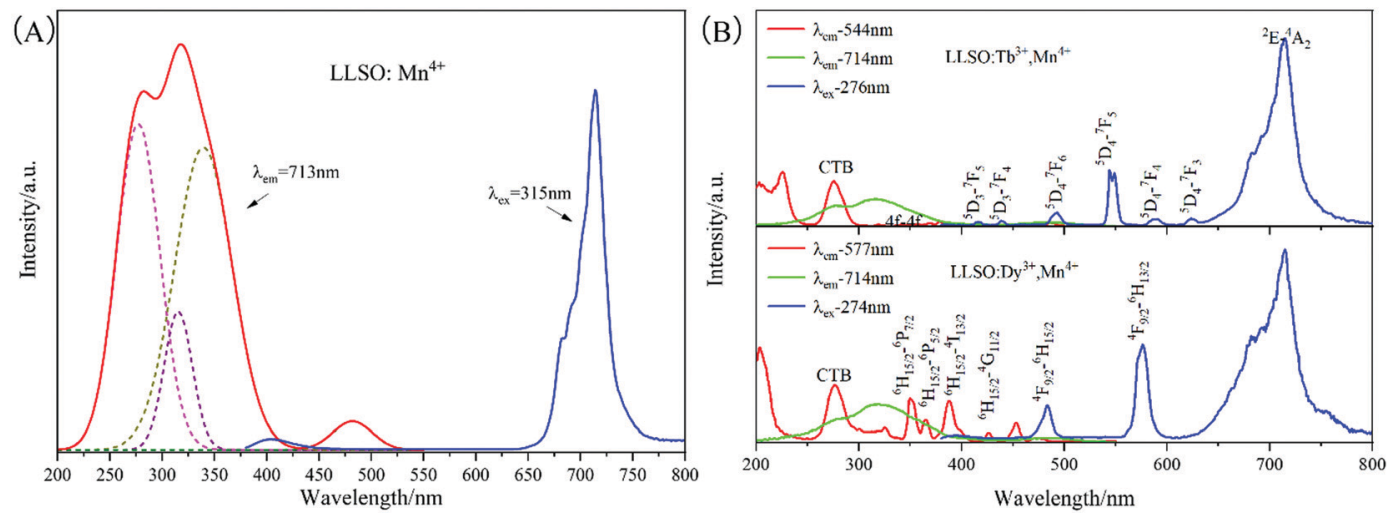

Fig. 3 The PL and PLE spectra of (A) LLSO: $0.005 \mathrm{Mn}^{4+}$; (B) LLSO: $0.09 \mathrm{~Tb}^{3+}, 0.005 \mathrm{Mn}^{4+}$ and LLSO: $0.09 \mathrm{Dy}^{3+}, 0.005 \mathrm{Mn}^{4+}$. 

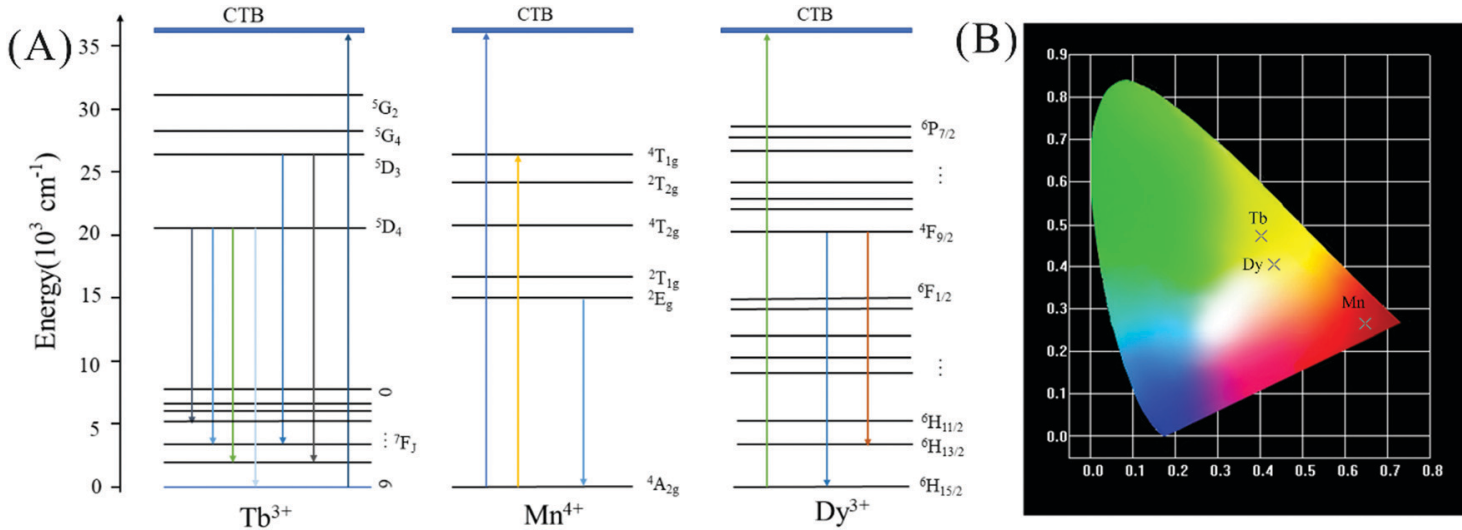

Fig. 4 (A) The light-emitting mechanism of $\mathrm{La}_{2} \mathrm{LiSbO}_{6}: \mathrm{Tb}^{3+} / \mathrm{Dy}^{3+}, \mathrm{Mn}^{4+}$ $0.005 \mathrm{Mn}^{4+}$ and LLSO: $0.09 \mathrm{Dy}^{3+}, 0.005 \mathrm{Mn}^{4+}$

well. On the basis of the excitation and emission spectra received, we conjecture that the possible luminescence mechanism for $\mathrm{Tb}^{3+} / \mathrm{Dy}^{3+}$ ions and $\mathrm{Mn}^{4+}$ ions co-doped LLSO phosphors is shown in Fig. 4(A). Under the excitation of $276 \mathrm{~nm}$ or $274 \mathrm{~nm}$, the electrons of $\mathrm{Mn}^{4+}$ immediately absorb energy, which is pumped from the ground state to the excited state, and then they relax to the low phonon energy ${ }^{2} \mathrm{E}_{\mathrm{g}}$ state through non-radiative relaxation. Ultimately, they return to the ground state and emit red light through radiative transitions. In the meantime, $\mathrm{Tb}^{3+}$ and $\mathrm{Dy}^{3+}$ ions are excited from the ground state to a higher excited state. Then, they are relaxed to the lower excited state through a nonradiative transition. Finally, they return to the ground state by releasing the observed photon radiation. CIE coordinates of these phosphors are shown in Fig. 4(B); the CIE coordinates of LLSO:0.005 $\mathrm{Mn}^{4+}$ phosphor are $(0.6481,0.2653)$ in the dark red region, and the CIE coordinates of LLSO:0.09 $\mathrm{Tb}^{3+} / 0.09 \mathrm{Dy}^{3+}, 0.005 \mathrm{Mn}^{4+}$ phosphors are $(0.4018$, $0.4721)$ and $(0.4319,0.4052)$ in the yellow-green region and light yellow region, respectively.

According to the PLE spectra of $\mathrm{Tb}^{3+} / \mathrm{Dy}^{3+}, \mathrm{Mn}^{4+}$ co-doped LLSO phosphors, we probed the emission spectra at different excitation wavelengths, as shown in Fig. 5(A) and (B). As can be
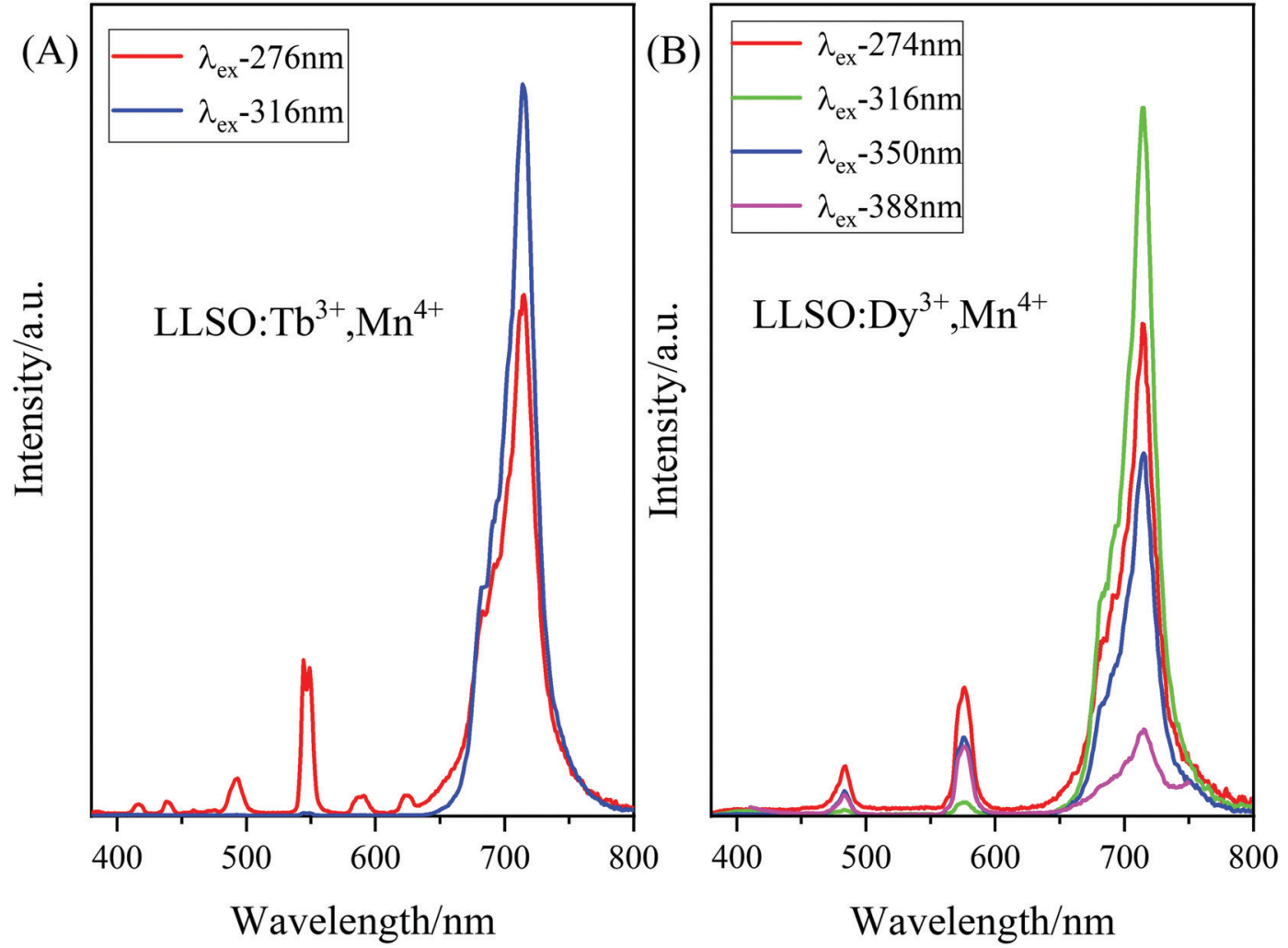

Fig. 5 The PL spectra of (A) $\mathrm{La}_{2} \mathrm{LiSbO}_{6}: 0.09 \mathrm{~Tb}^{3+}, 0.005 \mathrm{Mn}^{4+}$ and (B) LLSO: $0.09 \mathrm{Dy}^{3+}, 0.005 \mathrm{Mn}^{4+}$ excited at different wavelength. 

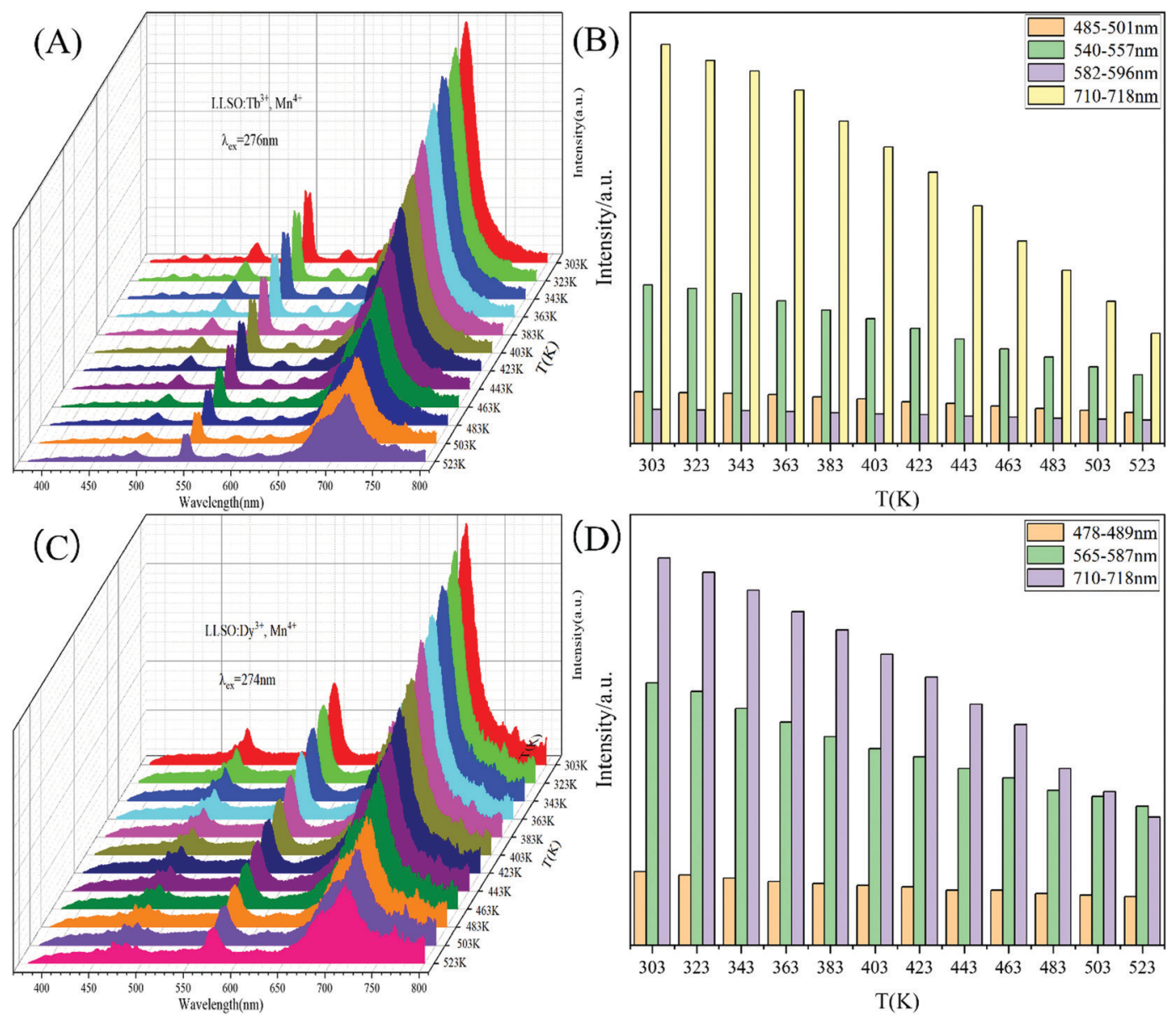

Fig. 6 The temperature-dependent PL spectra of (A) $\mathrm{La}_{2} \mathrm{LiSbO}_{6}: 0.09 \mathrm{~Tb}^{3+}, 0.005 \mathrm{Mn}^{4+}$ and (C) LLSO: $0.09 \mathrm{Dy}{ }^{3+}, 0.005 \mathrm{Mn}^{4+}$. (B), (D) The PL emission intensity of different band at various temperature.

seen from Fig. 5(A), the emission spectra of the LLSO: $\mathrm{Tb}^{3+}, \mathrm{Mn}^{4+}$ phosphor excited at $276 \mathrm{~nm}$ show the appearance of characteristic peaks of $\mathrm{Tb}^{3+}$ and $\mathrm{Mn}^{4+}$ ions, and the luminescence intensity was high. Similarly, as shown in Fig. 5(B), the emission spectra of the LLSO:Dy ${ }^{3+}, \mathrm{Mn}^{4+}$ phosphor excited at $274 \mathrm{~nm}$ show the

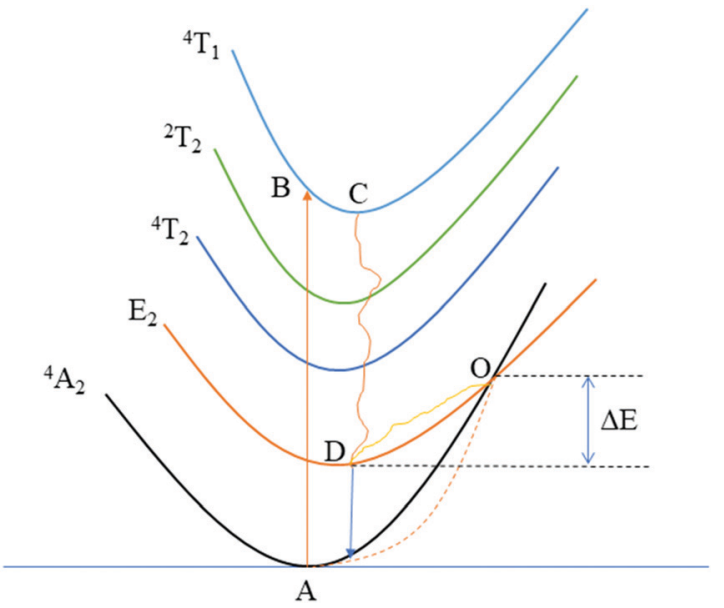

Fig. 7 Configurational coordinate diagrams of $\mathrm{Mn}^{4+}$ ions. characteristic peaks of $\mathrm{Dy}^{3+}$ and $\mathrm{Mn}^{4+}$ ions, and the luminescence intensity was high. Therefore, we chose $276 \mathrm{~nm}$ and $274 \mathrm{~nm}$ as the excitation wavelengths for the $\mathrm{Tb}^{3+} / \mathrm{Dy}^{3+}, \mathrm{Mn}^{4+}$ codoped phosphors to test the emission spectra at different temperatures.

In order to further explore the temperature-dependent properties of phosphors, PL spectra of LLSO:0.09 $\mathrm{Tb}^{3+} / 0.09 \mathrm{Dy}^{3+}, 0.005 \mathrm{Mn}^{4+}$ phosphors were monitored in the temperature range of 303-523 K, as shown in Fig. 6(A) and (C), respectively. With the increase of temperature, the luminescence intensity of $\mathrm{Tb}^{3+} / \mathrm{Dy}^{3+}$ and $\mathrm{Mn}^{4+}$ decreases, which is caused by heat quenching. The corresponding CIE colorimetric diagrams based on PL spectra at different temperatures are shown in Fig. S3 in the ESI. $\dagger$ As the temperature was increased from 303 to $523 \mathrm{~K}$, a significant change in $\operatorname{FIR~}\left(I_{\mathrm{Tb}} / I_{\mathrm{Mn}}\right)$ caused the transition of the chromaticity coordinates $(0.3754$, 0.4272 ) to $(0.3494,0.3898)$. Similarly, a significant change in FIR $\left(I_{\mathrm{Dy}} / I_{\mathrm{Mn}}\right)$ caused the transition of the chromaticity coordinates $(0.3826,0.3715)$ to $(0.3479,0.3514)$. We integrated the intensities of the characteristic peaks of each ion by area integral, and their column graphs are shown in Fig. 6(B) and (D). Obviously, the luminescence intensity of $\mathrm{Mn}^{4+}$ ions decreases much faster, which is due to the unique $3 \mathrm{~d}^{3}$ electron configuration of $\mathrm{Mn}^{4+}$ ions and is very sensitive to the external environment, resulting in stronger 

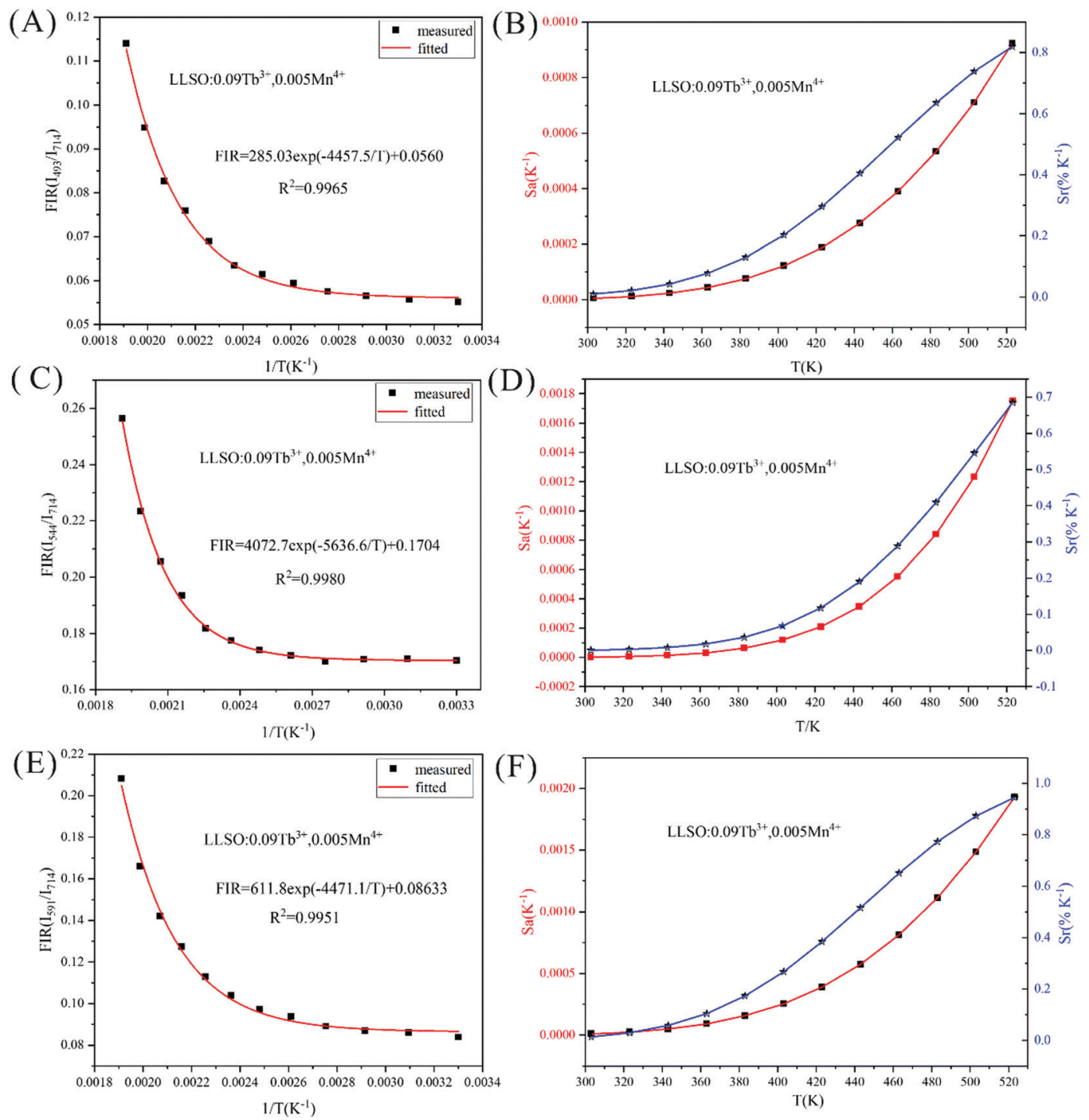

Fig. $8 \mathrm{FIR}$ values, $S_{r}$ and $S_{a}$ values of $\mathrm{La}_{2} \mathrm{LiSbO}_{6}: 0.09 \mathrm{~Tb}^{3+}, 0.005 \mathrm{Mn}^{4+}$ at different temperatures.

electron-phonon coupling and more intense heat quenching. Fig. 7 is the configuration coordinate diagram of $\mathrm{Mn}^{4+}$ in the LLSO host, which shows the possible thermal quenching mechanism of $\mathrm{Mn}^{4+}$. As shown in Fig. $7, \mathrm{Mn}^{4+}$ ions are first excited from the ${ }^{4} \mathrm{~A}_{2}$ state to the $\mathrm{B}$ point of the ${ }^{4} \mathrm{~T}_{1 \mathrm{~g}}$ state, and relaxed to the bottom $\mathrm{C}$ point of the excited state after losing partial energy, which is due to the instability of $\mathrm{Mn}^{4+}$ ions at point $\mathrm{B}$. Then it is relaxed to the $\mathrm{E}$ state through a nonradiative process, and then, by emitting red light (releasing photons) back to the ground state. However, with the increase in temperature, an increasing number of electrons in the ${ }^{2} \mathrm{E}$ state gain energy and get thermally excited, which makes them more willing to reach the intersection point of ${ }^{4} \mathrm{~A}_{2}$ and ${ }^{2} \mathrm{E}$ and then return to the ground state by radiation. The energy absorbed in this process is usually referred to as the activation energy of thermal quenching $(\Delta E)$. According to eqn (2), the $\Delta E$ values of $\mathrm{Tb}^{3+}$ ion and $\mathrm{Mn}^{4+}$ ion are $0.364 \mathrm{eV}$ and $0.255 \mathrm{eV}$, respectively; the $\Delta E$ values of $\mathrm{Dy}^{3+}$ ion and $\mathrm{Mn}^{4+}$ ion are $0.330 \mathrm{eV}$ and $0.256 \mathrm{eV}$, respectively. This is the reason why the thermal quenching of $\mathrm{Mn}^{4+}$ ion emission is faster than that of $\mathrm{Tb}^{3+} / \mathrm{Dy}^{3+}$ ions. This is very useful for temperature measurement based on FIR technology.

In order to explore the sensitivity of the co-doped phosphors, eqn (2) can be used to express the temperature dependence of the emission intensity according to Boltzmann distribution and thermal quenching mechanism. ${ }^{4,45}$

$$
I(T)=\frac{I_{0}}{1+A \exp \left(-\Delta E / k_{\mathrm{B}} T\right)}
$$

where $I_{0}$ is the emission intensity at the initial temperature (303 $\mathrm{K}$ in this work), $I(T)$ refers to the emission intensity at temperature $T$ (unit is $\mathrm{K}$ ), $A$ is a constant, $\Delta E$ is the activation energy of heat quenching, and $k_{\mathrm{B}}$ corresponds to the Boltzmann constant $\left(k_{\mathrm{B}}=8.629 \times 10^{5} \mathrm{eV} \mathrm{K}^{-1}\right)$. Considering a 

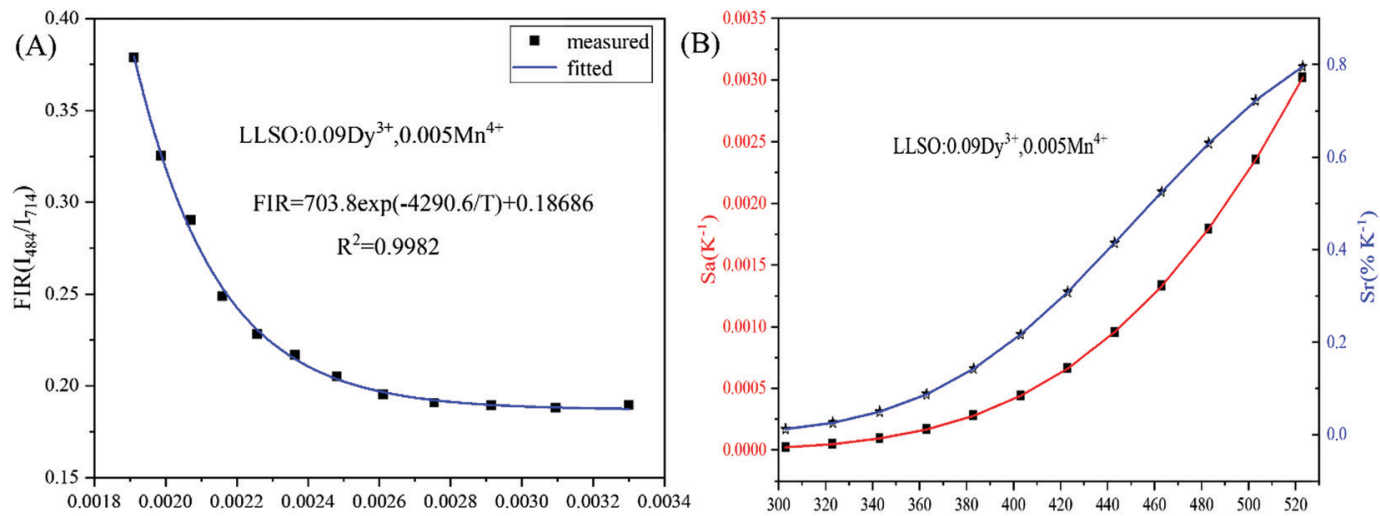

$1 / \mathrm{T}\left(\mathrm{K}^{-1}\right)$
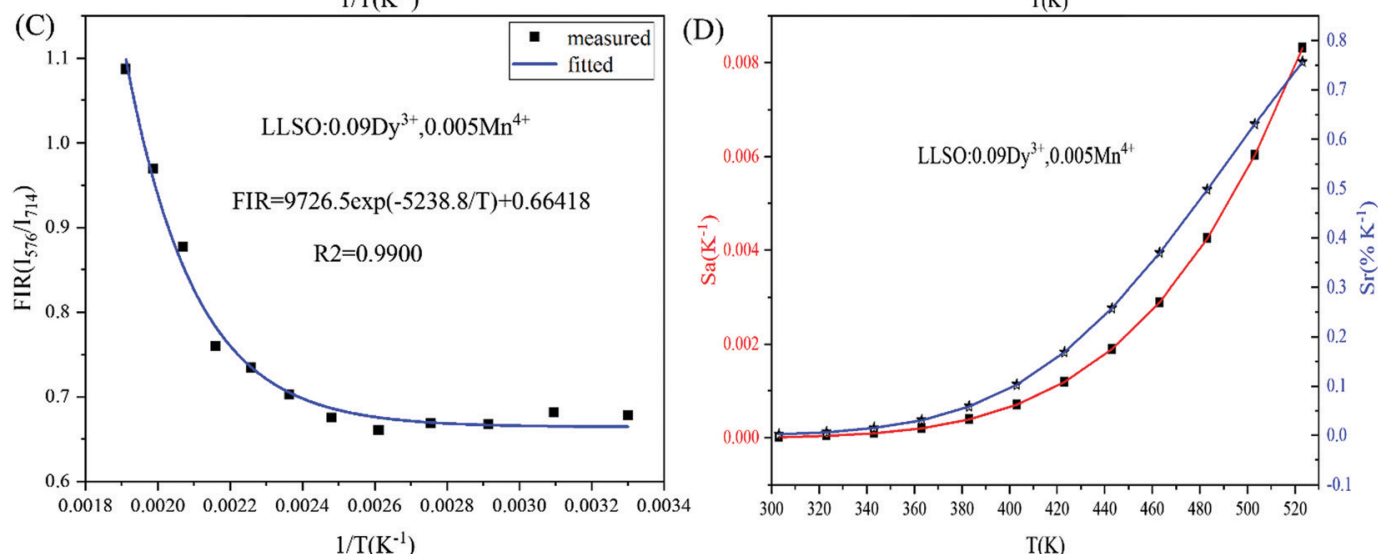

Fig. 9 FIR values, $S_{r}$ and $S_{a}$ values of $\mathrm{La}_{2} \mathrm{LiSbO}_{6}: 0.09 \mathrm{Dy}^{3+}, 0.005 \mathrm{Mn}^{4+}$ at different temperatures.

reasonable approximation, the temperature-dependent FIR of $\mathrm{Tb}^{3+} / \mathrm{Dy}^{3+}$ and $\mathrm{Mn}^{4+}$ can be expressed as:

$$
\begin{aligned}
\mathrm{FIR} & =\frac{I_{\mathrm{RE}}}{I_{\mathrm{Mn}}}=\frac{I_{0, \mathrm{RE}}}{I_{0, \mathrm{Mn}}} \frac{1+A_{\mathrm{Mn}} \times \exp \left(-\Delta E_{\mathrm{Mn}} / k_{\mathrm{B}} T\right)}{1+A_{\mathrm{RE}} \times \exp \left(-\Delta E_{\mathrm{RE}} / k_{\mathrm{B}} T\right)} \\
& \approx B+C \times \exp \left(-E / k_{\mathrm{B}} T\right)
\end{aligned}
$$

where $B$ and $C$ are constants, $E$ refers to the modified thermal quenching activation energy for the $\mathrm{RE}^{3+} / \mathrm{Mn}^{4+}$ dual-emitting system. The FIR values between $\mathrm{Tb}^{3+}$ and $\mathrm{Mn}^{4+}$ with different luminescence centers at different temperatures are shown in Fig. 8, and the FIR values between $\mathrm{Dy}^{3+}$ and $\mathrm{Mn}^{4+}$ with different luminescence centers at different temperatures are shown in Fig. 9. We use exponential fitting for these values, and the fitting relationship and fitting degree are presented in the figure. It can be seen from the figure that the exponential relationship between FIR and $1 / T$ fits very well. For temperature

Table 3 The maximum $S_{a}$ and $S_{r}$ values of $\mathrm{La}_{2} \mathrm{LiSbO}_{6}: 0.09 \mathrm{~Tb}^{3+} / \mathrm{Dy}^{3+}$ $0.005 \mathrm{Mn}^{4+}$ at different luminous centers

\begin{tabular}{llll}
\hline Doped ions & $\begin{array}{l}\text { Luminous } \\
\text { centers }(\mathrm{nm})\end{array}$ & $\begin{array}{l}\text { Maximum } \\
S_{\mathrm{a}}\left(\mathrm{K}^{-1}\right)\end{array}$ & $\begin{array}{l}\text { Maximum } \\
S_{\mathrm{r}}\left(\% \mathrm{~K}^{-1}\right)\end{array}$ \\
\hline $\mathrm{Tb}^{3+} / \mathrm{Mn}^{4+}$ & $493 / 714$ & 0.000924 & 0.820 \\
$\mathrm{~Tb}^{3+} / \mathrm{Mn}^{4+}$ & $544 / 714$ & 0.00175 & 0.686 \\
$\mathrm{~Tb}^{3+} / \mathrm{Mn}^{4+}$ & $591 / 714$ & 0.00193 & 0.946 \\
$\mathrm{Dy}^{3+} / \mathrm{Mn}^{4+}$ & $484 / 714$ & 0.00302 & 0.796 \\
$\mathrm{Dy}^{3+} / \mathrm{Mn}^{4+}$ & $576 / 714$ & 0.00832 & 0.757
\end{tabular}

sensing, sensitivity is a very important parameter to evaluate the performance of the temperature sensor. Absolute sensitivity $S_{\mathrm{a}}$ and relative sensitivity $S_{\mathrm{r}}$ can be defined as:

$$
\begin{aligned}
S_{\mathrm{a}} & =\left|\frac{\mathrm{d}(\mathrm{FIR})}{\mathrm{d}(T)}\right|=C \exp \left(-E / k_{\mathrm{B}} T\right) \times \frac{E}{k_{\mathrm{B}} T^{2}} \\
S_{\mathrm{r}} & =\left|\frac{1}{\text { FIR }} \times \frac{\mathrm{d}(\mathrm{FIR})}{\mathrm{d}(T)}\right| \times 100 \% \\
& =\frac{C \exp \left(-E / k_{\mathrm{B}} T\right)}{B+C \exp \left(-E / k_{\mathrm{B}} T\right)} \frac{E}{k_{\mathrm{B}} T^{2}} \times 100 \%
\end{aligned}
$$

The values of $S_{\mathrm{a}}$ and $S_{r}$ are calculated and shown in Fig. 8. The maximum values of $S_{\mathrm{a}}$ and $S_{\mathrm{r}}$ of different luminescent centers are shown in Table 3. Similarly, FIR values between $\mathrm{Dy}^{3+}$ and $\mathrm{Mn}^{4+}$ ions and corresponding $S_{\mathrm{a}}$ and $S_{\mathrm{r}}$ values of different luminous centers at different temperatures are shown in Fig. 9, and their maximum $S_{\mathrm{a}}$ and $S_{\mathrm{r}}$ values are shown in Table 3 . Obviously, with the increase of temperature, the relative temperature sensitivity and absolute temperature sensitivity are gradually improved, reaching the maximum at $523 \mathrm{~K}$. The maximum $S_{\mathrm{a}}$ and $S_{\mathrm{r}}$ of $\mathrm{Tb}^{3+}, \mathrm{Mn}^{4+}$ co-doped LLSO phosphor appeared in the $591 \mathrm{~nm} / 714 \mathrm{~nm}$ luminescence centers, which were $0.00193 \mathrm{~K}^{-1}$ and $0.946 \% \mathrm{~K}^{-1}$, respectively. The maximum $S_{\mathrm{a}}$ and $S_{\mathrm{r}}$ of $\mathrm{Dy}^{3+}, \mathrm{Mn}^{4+}$ co-doped LLSO phosphor appeared in the $576 \mathrm{~nm} / 714 \mathrm{~nm}$ luminescence centers, which were $0.00302 \mathrm{~K}^{-1}$ 
Table 4 Temperature sensing performances of several typical temperature sensors

\begin{tabular}{|c|c|c|c|c|c|c|}
\hline Hosts & Doped ions & Temperature range $(\mathrm{K})$ & Excitation wavelength (nm) & $S_{\mathrm{r}}\left(\% \mathrm{~K}^{-1}\right)$ & $S_{\mathrm{a}}\left(\mathrm{K}^{-1}\right)$ & Ref. \\
\hline $\mathrm{LaOBr}$ & $\mathrm{Ce}^{3+}, \mathrm{Tb}^{3+}$ & $293-433$ & 350 & 0.42 & - & 46 \\
\hline $\mathrm{LiNbO}_{3}$ & $\mathrm{Yb}^{3+}, \mathrm{Tm}^{3+}$ & $323-773$ & 980 & 0.7 & 0.0088 & 47 \\
\hline $\mathrm{Sr}_{3} \mathrm{GdNa}\left(\mathrm{PO}_{4}\right)_{3} \mathrm{~F}$ & $\mathrm{~Tb}^{3+}, \mathrm{Eu}^{3+}$ & $303-483$ & 275 & 0.16 & 0.00234 & 48 \\
\hline $\mathrm{K}_{3} \mathrm{LuF}_{6}$ & $\mathrm{Yb}^{3+}, \mathrm{Er}^{3+}$ & $300-773$ & 980 & 0.376 & - & 49 \\
\hline $\mathrm{Na}_{3} \mathrm{Sc}_{2} \mathrm{P}_{3} \mathrm{O}_{12}$ & $\mathrm{Eu}^{2+}, \mathrm{Mn}^{2+}$ & $293-473$ & 340 & 1.556 & - & 50 \\
\hline $\mathrm{SrY}_{2} \mathrm{O}_{4}$ & $\mathrm{Bi}^{3+}, \mathrm{Eu}^{3+}$ & $313-563$ & 330 & 0.86 & 0.0433 & 51 \\
\hline $\mathrm{Ca}_{2} \mathrm{YZr}_{2} \mathrm{Al}_{3} \mathrm{O}_{12}$ & $\mathrm{Bi}^{3+}, \mathrm{Eu}^{3+}$ & $297-573$ & 278 & 0.66 & 0.00826 & 52 \\
\hline BaLaMgNbO $_{6}$ & $\mathrm{Dy}^{3+}, \mathrm{Mn}^{4+}$ & $230-470$ & 355 & 1.82 & - & 53 \\
\hline $\mathrm{Lu}_{3} \mathrm{Al}_{5} \mathrm{O}_{12}$ & $\mathrm{~Tb}^{3+}, \mathrm{Mn}^{4+}$ & $270-420$ & 355 & 2.8 & 0.043 & 54 \\
\hline $\mathrm{Ca}_{2} \mathrm{LaNbO}_{6}$ & $\mathrm{Eu}^{3+}, \mathrm{Mn}^{4+}$ & $298-498$ & 396 & 1.51 & 0.0399 & 55 \\
\hline $\mathrm{NaLaMgWO}_{6}$ & $\mathrm{Eu}^{3+}, \mathrm{Mn}^{4+}$ & $303-523$ & 320 & 0.86 & 0.0302 & 41 \\
\hline $\mathrm{La}_{2} \mathrm{LiSbO}_{6}$ & $\mathrm{~Tb}^{3+}, \mathrm{Mn}^{4+}$ & $303-523$ & 276 & 0.946 & 0.00193 & This work \\
\hline $\mathrm{La}_{2} \mathrm{LiSbO}_{6}$ & $\mathrm{Dy}^{3+}, \mathrm{Mn}^{4+}$ & $303-523$ & 274 & 0.796 & 0.00302 & This work \\
\hline
\end{tabular}

and $0.796 \% \mathrm{~K}^{-1}$, respectively. The energy difference between $\mathrm{Tb}^{3+}(591 \mathrm{~nm}) / \mathrm{Dy}^{3+}(576 \mathrm{~nm})$ ions and $\mathrm{Mn}^{4+}(714 \mathrm{~nm})$ ions is about $2900 \mathrm{~cm}^{-1}$ and $3400 \mathrm{~cm}^{-1}$, which is much larger than the traditional TCLs of rare-earth ions. This indicates that the $S_{\mathrm{r}}$ of the phosphors with double luminescent centers is higher than that of the phosphors based on TCLs, which is traceable. These $S_{\mathrm{r}}$ and $S_{\mathrm{a}}$ are comparable to many other typical co-doped systems listed in Table 4 . In addition, temperature resolution $(\delta T)$ is also an important index to reflect the temperature measurement performance of thermometers, which can be defined as:

$$
\delta T=\frac{1}{S_{\mathrm{r}}} \times \frac{\partial \Delta}{\Delta}
$$

where $\partial \Delta / \Delta$ represents the relative error and its value is about $0.5 \%$ in temperature measurement by FIR technology. Because of their excellent relative sensitivity, the minimum resolutions of LLSO:0.09 $\mathrm{Tb}^{3+}, 0.005 \mathrm{Mn}^{4+}$ phosphors and LLSO:0.09Dy ${ }^{3+}, 0.005 \mathrm{Mn}^{4+}$ phosphors are $0.529 \mathrm{~K}$ and $0.628 \mathrm{~K}$, respectively. The peak positions of $\mathrm{Mn}^{4+}$ and $\mathrm{Tb}^{3+} / \mathrm{Dy}^{3+}$ are separated, which can provide a good signal discrimination performance. The results show that LLSO: $0.09 \mathrm{~Tb}^{3+} / \mathrm{Dy}^{3+}, 0.005 \mathrm{Mn}^{4+}$ samples are suitable for optical thermometers.

\section{Conclusion}

In all, we have successfully constructed a dual-luminescent system of $\mathrm{Tb}^{3+} / \mathrm{Dy}^{3+}, \mathrm{Mn}^{4+}$ co-doped antimonate by using a green synthesis method, which is based on the site-beneficial occupation principle. When $\mathrm{Tb}^{3+} / \mathrm{Dy}^{3+}$ ions and $\mathrm{Mn}^{4+}$ ions enter the matrix, they will occupy different cation sites, in which $\mathrm{Mn}^{4+}$ ions will replace $\mathrm{Sb}^{5+}$ sites in the matrix, and $\mathrm{Tb}^{3+} / \mathrm{Dy}^{3+}$ ions can be doped into $\mathrm{La}^{3+}$ sites. By analyzing their luminescence spectra, the emission of $\mathrm{Tb}^{3+} / \mathrm{Dy}^{3+}$ ions and $\mathrm{Mn}^{4+}$ ions can be simultaneously observed under excitation at $276 \mathrm{~nm}$ or $274 \mathrm{~nm}$ and the intensity is very ideal. On this basis, their possible luminescence mechanism is speculated.

Because of the different thermal quenching behavior between RE ions and TM ions, the emission intensity of $\mathrm{Mn}^{4+}$ is much faster than that of $\mathrm{Tb}^{3+}$ and $\mathrm{Dy}^{3+}$ ions with the increase in temperature. Therefore, $\mathrm{Tb}^{3+} / \mathrm{Dy}^{3+}$ ions can be used as reference signals, whereas $\mathrm{Mn}^{4+}$ ions are suitable detection signals. The fluorescence intensity ratio (FIR) of $\mathrm{Tb}^{3+} / \mathrm{Dy}^{3+}$ ions and $\mathrm{Mn}^{4+}$ ions are significantly affected by temperature. Therefore, the material exhibits excellent temperature measurement performance in the temperature range of 303-523 K. Based on FIR technology, the maximum relative sensitivity and absolute sensitivity of $\mathrm{Tb}^{3+}$ and $\mathrm{Mn}^{4+}$ co-doped LLSO phosphors are $0.946 \% \mathrm{~K}^{-1}(523 \mathrm{~K})$ and $0.00193 \mathrm{~K}^{-1}$, respectively; the maximum relative sensitivity and absolute sensitivity of $\mathrm{Dy}^{3+}$ and $\mathrm{Mn}^{4+}$ co-doped LLSO phosphors are $0.796 \% \mathrm{~K}^{-1}$ and $0.00832 \mathrm{~K}^{-1}$, respectively, which are much higher than those of some optical thermometric materials reported previously. In addition, the emission peaks of $\mathrm{Tb}^{3+} / \mathrm{Dy}^{3+}$ ions and $\mathrm{Mn}^{4+}$ ions are well separated, which provides a good signal identification ability for temperature detection. This work hews out a new strategy to develop high-performance optical temperature sensing materials that have extensive application potentiality in non-contact temperature detection.

\section{Conflicts of interest}

There are no conflicts of interest to declare.

\section{Acknowledgements}

This work is financially supported by the National Natural Science Foundation of China (Grant No. 21401130); the Opening Research Fund of the State Key Laboratory of Rare Earth Resource Utilization, Changchun Institute of Applied Chemistry, Chinese Academy of Sciences (RERU2014005).

\section{References}

1 D. Peng, B. Chen and F. Wang, Recent Advances in Doped Mechanoluminescent Phosphors, ChemPlusChem, 2015, 80, 1209-1215.

2 Q. Ju, D. Tu, Y. Liu, R. Li, H. Zhu, J. Chen, Z. Chen, M. Huang and X. Chen, Amine-Functionalized LanthanideDoped $\mathrm{KGdF}_{4}$ Nanocrystals as Potential Optical/Magnetic Multimodal BioProbes, J. Am. Chem. Soc., 2012, 134, 1323-1330. 
3 M. Shang, S. Huang and J. Lin, Multicolor emissions and photoluminescence properties for $\mathrm{Ca}_{3} \mathrm{Al}_{4} \mathrm{ZnO}_{10}: \mathrm{Ce}^{3+} / \mathrm{Eu}^{3+} /$ $\mathrm{Tb}^{3+} / \mathrm{Mn}^{2+}$ phosphors, J. Lumin., 2018, 204, 493-498.

4 M. Chen, Z. Xia and Q. Liu, Ethylenediamine-Assisted Hydrothermal Synthesis of $\mathrm{NaCaSiO}_{3} \mathrm{OH}$ : Controlled Morphology, Mechanism, and Luminescence Properties by Doping $\mathrm{Eu}^{3+} / \mathrm{Tb}^{3+}$, Inorg. Chem., 2016, 55, 11316-11322.

5 Q. Zeng, P. He, H. Liang, M. Gong and Q. Su, Luminescence of $\mathrm{Eu}^{3+}$-activated tetra-molybdate red phosphors and their application in near-UV InGaN-based LEDs, Mater. Chem. Phys., 2009, 118, 76-80.

6 L. Wang, R.-J. Xie, Y. Li, X. Wang, C.-G. Ma, D. Luo, T. Takeda, Y.-T. Tsai, R.-S. Liu and N. Hirosaki, $\mathrm{Ca}_{1-x} \mathrm{Li}_{x-}$ $\mathrm{Al}_{1-x} \mathrm{Si}_{1+x} \mathrm{~N}_{3}: \mathrm{Eu}^{2+}$ solid solutions as broadband, colortunable and thermally robust red phosphors for superior color rendition white light-emitting diodes, Light: Sci. Appl., 2016, 5, e16155.

7 L. Feng, Z. Hao, X. Zhang, L. Zhang, G. Pan, Y. Luo, L. Zhang, H. Zhao and J. Zhang, Red emission generation through highly efficient energy transfer from $\mathrm{Ce}^{3+}$ to $\mathrm{Mn}^{2+}$ in $\mathrm{CaO}$ for warm white LEDs, Dalton Trans., 2016, 45, 1539-1545.

8 C. Wang, Y. Jin, L. Yuan, H. Wu, G. Ju, Z. Li, D. Liu, Y. Lv, L. Chen and Y. Hu, A spatial/temporal dual-mode optical thermometry platform based on synergetic luminescence of $\mathrm{Ti}^{4+}-\mathrm{Eu}^{3+}$ embedded flexible 3D micro-rod arrays: Highsensitive temperature sensing and multi-dimensional high-level secure anti-counterfeiting, Chem. Eng. J., 2019, 374, 992-1004.

9 L. Li, X. Tang, Z. Wu, Y. Zheng, S. Jiang, X. Tang, G. Xiang and $\mathrm{X}$. Zhou, Simultaneously tuning emission color and realizing optical thermometry via efficient $\mathrm{Tb}^{3+} \rightarrow \mathrm{Eu}^{3+}$ energy transfer in whitlockite-type phosphate multifunctional phosphors, J. Alloys Compd., 2019, 780, 266-275.

10 Z. Cao, S. Zhou, G. Jiang, Y. Chen, C. Duan and M. Yin, Temperature dependent luminescence of $\mathrm{Dy}^{3+}$ doped BaYF5 nanoparticles for optical thermometry, Curr. Appl. Phys., 2014, 14, 1067-1071.

11 W. Dai, J. Hu, G. Liu, S. Xu, K. Huang, J. Zhou and M. Xu, Thermometer of stable $\mathrm{SrAl}_{2} \mathrm{Si}_{2} \mathrm{O}_{8}: \mathrm{Ce}^{3+}, \mathrm{Tb}^{3+}$ based on synergistic luminescence, J. Lumin., 2020, 217, 116807.

12 B. Dong, D. P. Liu, X. J. Wang, T. Yang, S. M. Miao and C. R. Li, Optical thermometry through infrared excited green upconversion emissions in $\mathrm{Er}^{3+}-\mathrm{Yb}^{3+}$ codoped $\mathrm{Al}_{2} \mathrm{O}_{3}$, Appl. Phys. Lett., 2007, 90, 181117.

13 Y. Fu, L. Zhao, Y. Guo and H. Yu, A transparent and dualfunctional oxyfluoride glass ceramics with color-tunable upconversion luminescence and high thermosensitivity, J. Lumin., 2020, 217, 116807.

14 H. Zhang, Z. Gao, G. Li, Y. Zhu, S. Liu, K. Li and Y. Liang, A ratiometric optical thermometer with multi-color emission and high sensitivity based on double perovskite LaMg0.402Nb0.59803: $\operatorname{Pr}^{3+}$ thermochromic phosphors, Chem. Eng. J., 2020, 380, 122491.

15 Z. Xing, P. Li, S. Wu, C. Liu, D. Dai, X. Li, L. Zhang, D. Wang, Z. Yang and Z. Wang, A perovskite-like $\mathrm{LaSrGaO}_{4}: \mathrm{Mn}^{2+}$,
$\mathrm{Nd}^{3+}, \mathrm{Y}^{3+} \mathrm{NIR}$ luminescent material for fluorescent temperature sensor, J. Lumin., 2020, 225, 117352.

16 E. J. McLaurin, L. R. Bradshaw and D. R. Gamelin, DualEmitting Nanoscale Temperature Sensors, Chem. Mater., 2013, 25, 1283-1292.

17 X. Wang, Q. Liu, Y. Bu, C.-S. Liu, T. Liu and X. Yan, Optical temperature sensing of rare-earth ion doped phosphors, RSC Adv., 2015, 5, 86219-86236.

18 J. Tang, P. Du, W. Li and L. Luo, Boosted thermometric performance in $\mathrm{NaGdF}_{4}: \mathrm{Er}^{3+} / \mathrm{Yb}^{3+}$ upconverting nanorods by $\mathrm{Fe}^{3+}$ ions doping for contactless nanothermometer based on thermally and non-thermally coupled levels, J. Lumin., 2020, 224, 117296.

19 P. Kaur, A. Khanna, M. N. Singh and A. K. Sinha, Structural and optical characterization of $\mathrm{Eu}$ and Dy doped $\mathrm{CaWO}_{4}$ nanoparticles for white light emission, J. Alloys Compd., 2020, 834, 154804.

20 J. Huang, L. Tang, N. Chen and G. Du, Broadening the Photoluminescence Excitation Spectral Bandwidth of $\mathrm{YVO}_{4}: \mathrm{Eu}^{3+}$ Nanoparticles via a Novel Core-Shell and Hybridization Approach, Materials, 2019, 12, 3830.

21 X. Miao, Z. Bai, G. Qiu, S. Tang, M. Guo, F. Cheng and M. Zhang, Preparation of transparent $\mathrm{Mn}$-doped $\mathrm{CaF}_{2}$ glassceramics from silicon-manganese slag: Dependence of colour-controllable change on slag addition and crystallization behavior, J. Eur. Ceram. Soc., 2020, 40, 3249-3261.

22 T. Wang, S. Wang, H. Zhang, X. Zou and W. Hu, Tm ${ }^{3+}-\mathrm{Dy}^{3+}{ }_{-}$ $\mathrm{Eu}^{3+}$ tri-doped transparent glass-ceramics containing $\mathrm{NaY}\left(\mathrm{MoO}_{4}\right)_{(2)}$ crystal phase: Preparation, energy transfer, warm white light emitting, Opt. Mater., 2020, 104, UNSP 109851.

23 B. R. Reddy, I. Kamma and P. Kommidi, Optical sensing techniques for temperature measurement, Appl. Opt., 2013, 52, B33-B39.

24 S. F. Collins, G. W. Baxter, S. A. Wade, T. Sun, K. T. V. Grattan, Z. Y. Zhang and A. W. Palmer, Comparison of fluorescence-based temperature sensor schemes: theoretical analysis and experimental validation, J. Appl. Phys., 1998, 84, 4649-4654.

25 V. Dubey, S. Agrawal and J. Kaur, Photoluminescence and thermoluminescence behavior of Gd doped $\mathrm{Y}_{2} \mathrm{O}_{3}$ phosphor, Optik, 2015, 126, 1-5.

26 M. Benabdesselam, F. Mady and S. Girard, Assessment of Ge-doped optical fibre as a TL-mode detector, J. Non-Cryst. Solids, 2013, 360, 9-12.

27 Z. Zhou, J. Zheng, R. Shi, N. Zhang, J. Chen, R. Zhang, H. Suo, E. M. Goldys and C. Guo, Ab Initio Site Occupancy and Far-Red Emission of $\mathrm{Mn}^{4+}$ in Cubic-Phase $\mathrm{La}(\mathrm{MgTi})_{1 / 2} \mathrm{O}_{3}$ for Plant Cultivation, ACS Appl. Mater. Interfaces, 2017, 9, 6177-6185.

28 M. Sekulic, Z. Ristic, B. Milicevic, Z. Antic, V. Dordevic and M. D. Dramicanin, $\mathrm{Li}_{1.8} \mathrm{Na}_{0.2} \mathrm{TiO}_{3}: \mathrm{Mn}^{4+}$ : the highly sensitive probe for the low-temperature lifetime-based luminescence thermometry, Opt. Commun., 2019, 452, 342-346.

29 I. E. Kolesnikov, A. A. Kalinichev, M. A. Kurochkin, E. Y. Kolesnikov and E. Lahderanta, Porphyrins as efficient 
ratiometric and lifetime-based contactless optical thermometers, Mater. Des., 2019, 184, 108188.

30 S. A. Wade, S. F. Collins and G. W. Baxter, Fluorescence intensity ratio technique for optical fiber point temperature sensing, J. Appl. Phys., 2003, 94, 4743.

31 D. He, C. Guo, S. Jiang, N. Zhang, C. Duan, M. Yin and T. Li, Optical temperature sensing properties of $\mathrm{Yb}^{3+}-\mathrm{Er}^{3+}$ codoped $\mathrm{NaLnTiO}_{4}(\mathrm{Ln}=\mathrm{Gd}, \mathrm{Y})$ up-conversion phosphors, RSC Adv., 2015, 5, 1385-1390.

32 D. Wawrzynczyk, A. Bednarkiewicz, M. Nyk, W. Strek and M. Samoc, Neodymium(III) doped fluoride nanoparticles as non-contact optical temperature sensors, Nanoscale, 2012, 4, 6959-6961.

33 L. Zhao, Z. Cao, X. Wei, M. Yin and Y. Chen, Luminescence properties of $\mathrm{Eu}^{3+}$ doped $\mathrm{YBO}_{3}$ for temperature sensing, J. Rare Earths, 2017, 35, 356-360.

34 Z. Liang, F. Qin, Y. Zheng, Z. Zhang and W. Cao, Noncontact thermometry based on downconversion luminescence from $\mathrm{Eu}^{3+}$ doped $\mathrm{LiNbO}_{3}$ single crystal, Sens. Actuators, A, 2016, 238, 215-219.

35 Y. Ma, G. Xiang, J. Zhang, Z. Liu, P. Zhou, W. Liu, X. Tang, S. Jiang, X. Zhou, L. Li, Y. Luo and Y. Jin, Upconversion properties and temperature sensing behaviors in visible and near-infrared region based on fluorescence intensity ratio in $\mathrm{LuVO}_{4}: \mathrm{Yb}^{3+} / \mathrm{Er}^{3+}$, J. Alloys Compd., 2018, 769, 325-331.

36 K. Li, D. Zhu and H. Lian, Up-conversion luminescence and optical temperature sensing properties in novel $\mathrm{KBaY}\left(\mathrm{MoO}_{4}\right)_{(3)}: \mathrm{Yb}^{3+}, \mathrm{Er}^{3+}$ materials for temperature sensors, J. Alloys Compd., 2020, 816, 152554.

37 H. Zhang, H. Zhang, B. Lei, N. Lai, X. Lin, H. Lu, Q. Lan and Y. Liu, High Temperature Solid-State Synthesis and Luminescent Properties of $\mathrm{Sr}_{2} \mathrm{MgAl}_{22} \mathrm{O}_{36}: \mathrm{Mn}^{4+}$, Rare Met. Mater. Eng., 2016, 45, 448-452.

38 X. Huang, Q. Sun and B. Devakumar, Novel efficient deepred-emitting $\mathrm{Ca}_{2} \mathrm{LuTaO}_{6}: \mathrm{Mn}^{4+}$ double-perovskite phosphors for plant growth LEDs, J. Lumin., 2020, 222, 117177.

39 M. Liu, P. Dang, Y. Wei, S. Liang, G. Liu, A. Geng, H. Lian and J. Lin, Comparative analysis on the photoluminescence properties of $\mathrm{Cs}_{2} \mathrm{BF}_{6}: \mathrm{Mn}^{4+}(\mathrm{B}=\mathrm{Ge}, \mathrm{Si}, \mathrm{Zr}, \mathrm{Ti})$ red phosphors for WLEDs, J. Am. Ceram. Soc., 2020, 103, 1197-1208.

40 Y. Song, N. Guo, J. Li, R. Ouyang, Y. Miao and B. Shao, Photoluminescence and temperature sensing of lanthanide $\mathrm{Eu}^{3+}$ and transition metal $\mathrm{Mn}^{4+}$ dual-doped antimoniate phosphor through site-beneficial occupation, Ceram. Int., 2020, 46, 22164-22170.

41 H. Zhou, N. Guo, M. Zhu, J. Li, Y. Miao and B. Shao, Photoluminescence and ratiometric optical thermometry in $\mathrm{Mn}^{4+} / \mathrm{Eu}^{3+}$ dual-doped phosphor via site-favorable occupation, J. Lumin., 2020, 224, 117311.

42 M. L. López, M. L. Veiga, A. Jerez and C. Pico, Synthesis and crystal structure of La2LiSbO6, Mater. Rer. Bull., 1990, 25, 1271-1277.
43 A. M. Pires and M. R. Davolos, Luminescence of europium(III) and manganese(II) in barium and zinc orthosilicate, Chem. Mater., 2001, 13, 21-27.

44 X. Wang, Z. Zhao, Q. Wu, Y. Li and Y. Wang, A Garnet-Based $\mathrm{Ca}_{2} \mathrm{YZr}_{2} \mathrm{Al}_{3} \mathrm{O}_{12}: \mathrm{Eu}^{3+}$ Red-Emitting Phosphor for n-UV Light Emitting Diodes and Field Emission Displays: Electronic Structure and Luminescence Properties, Inorg. Chem., 2016, 55, 11072-11077.

45 Y. Gao, F. Huang, H. Lin, J. Zhou, J. Xu and Y. Wang, A Novel Optical Thermometry Strategy Based on Diverse Thermal Response from Two Intervalence Charge Transfer States, Adv. Funct. Mater., 2016, 26, 3139-3145.

46 X. Zhang, Y. Huang and M. Gong, Dual-emitting $\mathrm{Ce}^{3+}, \mathrm{Tb}^{3+}$ co-doped LaOBr phosphor: luminescence, energy transfer and ratiometric temperature sensing, Chem. Eng. J., 2017, 307, 291-299.

47 L. Xing, R. Ao, Y. Liu and W. Yang, Optical thermometry based on the non-thermally coupled levels of Tm(III) in $\mathrm{LiNbO}_{3}$ crystals, Spectrochim. Acta, Part A, 2019, 222, 117159.

48 N. Guo, Y. Pan, W. Lv, R. Ouyang and B. Shao, Optical thermometric properties in $\mathrm{Tb}^{3+}$ and $\mathrm{Eu}^{3+}$-coactivated dualemissive fluorophosphate phosphors, Opt. Laser Technol., 2020, 123(105938).

49 J. Cao, F. Hu, L. Chen, H. Guo, C. Duan and M. Yin, Widerange thermometry based on green up-conversion luminescence of $\mathrm{K}_{3} \mathrm{LuF}_{6}: \mathrm{Yb}^{3+} / \mathrm{Er}^{3+}$ bulk oxyfluoride glass ceramics, J. Am. Ceram. Soc., 2017, 100, 2108-2115.

50 X. Zhang, Z. Zhu, Z. Guo, Z. Sun and Y. Chen, A ratiometric optical thermometer with high sensitivity and superior signal discriminability based on $\mathrm{Na}_{3} \mathrm{Sc}_{2} \mathrm{P}_{3} \mathrm{O}_{12}: \mathrm{Eu}^{2+}, \mathrm{Mn} 2+$ thermochromic phosphor, Chem. Eng. J., 2019, 356, 413-422.

51 R. Wei, J. Guo, K. Li, L. Yang, X. Tian, X. Li, F. Hu and H. Guo, Dual-emitting $\mathrm{SrY}_{2} \mathrm{O}_{4}: \mathrm{Bi}^{3+}, \mathrm{Eu}^{3+}$ phosphor for ratiometric temperature sensing, J. Lumin., 2019, 216, 116737.

52 Z. Zheng, J. Zhang, X. Liu, R. Wei, F. Hu and H. Guo, Luminescence and self-referenced optical temperature sensing performance in $\mathrm{Ca}_{2} \mathrm{YZr}_{2} \mathrm{Al}_{3} \mathrm{O}_{12}: \mathrm{Bi}^{3+}, \mathrm{Eu}^{3+}$ phosphors, Ceram. Int., 2020, 46, 6154-6159.

53 Y. Lin, L. Zhao, B. Jiang, J. Mao, F. Chi, P. Wang, C. Xie, X. Wei, Y. Chen and M. Yin, Temperature-dependent luminescence of BaLaMgNbO 6 : $\mathrm{Mn}^{4+}$, $\mathrm{Dy}^{3+}$ phosphor for dual-mode optical thermometry, Opt. Mater., 2019, 95, UNSP 109199.

54 C. Xie, L. Zhao, B. Jiang, J. Mao, Y. Lin, P. Wang, X. Wei, M. Yin and Y. Chen, Dual-activator luminescence of LuAG: $\mathrm{Mn}^{4+} / \mathrm{Tb}^{3+}$ phosphor for optical thermometry, J. Am. Ceram. Soc., 2019, 102, 7500-7508.

55 P. Wang, J. Mao, L. Zhao, B. Jiang, C. Xie, Y. Lin, F. Chi, M. Yin and Y. Chen, Double perovskite $\mathrm{A}_{2} \mathrm{LaNbO}_{6}: \mathrm{Mn}^{4+}$, $\mathrm{Eu}^{3+}(\mathrm{A}=\mathrm{Ba}, \mathrm{Ca})$ phosphors: potential applications in optical temperature sensing, Dalton Trans., 2019, 48, 10062-10069. 